\title{
THE CONCEPTUAL NATURE OF IMAGINATIVE CONTENT ${ }^{*}$
}

\author{
Margherita Arcangeli \\ Institut Jean Nicod (CNRS-EHESS-ENS), PSL University
}

\begin{abstract}
Imagination is widely thought to come in two varieties: perception-like and belief-like imagination. What precisely sets them apart, however, is not settled. More needs to be said about the features that make one variety perception-like and the other belief-like. One common, although typically implicit, view is that they mimic their counterparts (perception and belief, respectively) along the conceptuality dimension: while the content of belief-like imagination is fully conceptual, the content of perception-like imagination is fully (or at least partially) non-conceptual. Such a view, however, is not sufficiently motivated in the literature. I will show that there are good reasons to reject it and I will argue that both varieties of imagination involve fully conceptual contents (independently of whether either perception or belief has non-conceptual content). I will suggest an alternative way to draw the distinction between perception-like and belief-like imagination along the conceptuality dimension, according to which only perception-like imagination requires observational concepts.
\end{abstract}

Keywords Perception-like/Sensory imagination · Belief-like/Cognitive imagination · Conceptual content $\cdot$ Non-conceptual content $\cdot$ Observational concepts

\section{INTRODUCTION}

Imagination is widely thought to come in (at least) two varieties: a sensory variety and a non-sensory or cognitive one. Different labels have been used to capture such a distinction, or something like it: “objectual” vs. "propositional” imagination (Yablo 1993), "perceptual” or "perception-like" vs. "belieflike" imagination (e.g., Currie \& Ravenscroft 2002), "sensory" vs. "cognitive" imagination (e.g., McGinn 2004), “attitudinal” vs. "imagistic" imagining (see Kind 2016).

Despite some divergences among taxonomies, ${ }^{1}$ a common thought is that while the sensory variety (hereafter S-Imagination) is in a relevant sense similar to perception, the cognitive variety (hereafter C-Imagination) is akin to belief. However, it is far from clear what exactly sets these two varieties of imagination apart. Saying that $\mathrm{S}$-imagination and $\mathrm{C}$-imagination mimic perception and belief, respectively, is not very informative as such. More should be said about what features make

\footnotetext{
* I am indebted to Dimitri Coelho Mollo, Jérôme Dokic, Uriah Kriegel and anonymous referees for critical and helpful comments on earlier versions of this paper. This research has been funded by the SublimAE Project (ANR-18-CE270023-01), with the further support of the ANR-17-EURE-0017 FrontCog and the ANR-10-IDEX-0001-02 PSL.

${ }^{1}$ For instance, it is an open question whether objectual imaginings coincide with perceptual imaginings (see Kind 2013; Arcangeli 2018).
} 
the former perception-like and the latter belief-like. Moreover, we might wonder why we should consider S-imagination and C-imagination as species of the same genus (viz. imagination), rather than two different kinds of mental state, as it is typically granted for their counterparts - to borrow Currie and Ravenscroft's (2002) term - namely perception and belief. It is crucial to investigate further what S-Imagination and C-Imagination are and how they are related, in order to shed light on the nature of imagination tout court.

In this paper I shall focus on a neglected dimension of our imaginings, namely their conceptuality. This is in contrast to current philosophical work on the imagination, which concentrates attention on propositionality. C-imagination is often contrasted with S-Imagination on the basis that the former has propositional content (one imagines that something is the case), whereas the latter does not. ${ }^{2}$ For instance, Currie and Ravenscroft (2002) state that while SImagination belongs to perceptual imaginings, C-Imagination belongs to propositional imaginings. Similarly, McGinn defines C-Imagination in opposition to S-Imagination as the variety of imagination which "employs conceptual elements" that "combine to form propositional contents" (McGinn 2004, p. 129).

Propositionality and conceptuality are rarely distinguished in analyses of the imagination, as McGinn's point illustrates. However, the relationship between propositionality and conceptuality is notoriously complex, and arguably they should not be taken to be equivalent. The literature recognises double dissociations: propositional content need not be conceptual (cf. Russellian propositions), and conceptual content need not be propositional (McDowell 2008; Crane 2009). Here I want to explore conceptuality as a dimension theoretically independent from propositionality.

Conceptuality has been used (more implicitly than explicitly) to capture the distinction between C-Imagination and S-Imagination, as follows: while the content of the former is conceptual, the content of the latter is non-conceptual. This claim can be interpreted more or less radically depending on whether it aims at fully or partially capturing the contents of C-Imagination and S-Imagination. In what follows I will grant that C-Imagination has fully conceptual content and will show that there are reasons to reject both the idea that S-Imagination has fully non-conceptual content and the idea that it has only partially non-conceptual content.

After introducing the conceptual/non-conceptual distinction as regards perception and belief (§2), I will argue that while the conceptuality of C-Imagination content is highly plausible, the nonconceptuality of S-Imagination content is dubious, given the dependence of imagination (even in its

\footnotetext{
${ }^{2}$ This argument parallels one of the arguments that distinguish belief and perception in terms of their contents. However, propositionality is arguably unfitting for providing a clear-cut distinction between belief and perception, insofar as the content of belief can be non-propositional (see Szabó 2003), and the content of (at least a type of) perception propositional (see Dretske 1969 on epistemic perception). Worries can be raised against propositionality also as a means to grasp the distinction between C-Imagination and S-Imagination (see Arcangeli 2018).
} 
sensory variety) on conceptual knowledge. I will consider four arguments in favour of the idea that the content of S-Imagination is (fully or partially) non-conceptual and show that they fail. I will suggest that the content of S-Imagination is instead fully conceptual, even if perceptual content turns out to be fully non-conceptual (§3). My view keeps a principled distinction between S-Imagination and CImagination, and I will conclude by sketching an alternative positive account of this distinction at the level of the contents of the relevant imaginings. In a nutshell, even though both varieties of imagination have conceptual contents, S-Imagination requires specific concepts, namely observational ones, which can be exploited but are not required by C-Imagination $(\S 4)$.

\section{CONCEPTUALITY FOR PERCEPTION AND BELIEF}

Suppose Jacob is in a garden where there are both beeches and birches. He does not know exactly how beeches and birches look. In fact, Jacob does not possess the concepts of birch and beech; he merely knows that the words "birch" and "beech" refer to different kinds of tree. Nevertheless, Jacob can see, for instance, the difference between two kinds of bark, a rough one marked with long horizontal lenticels and a smooth grey one. Arguably, then, he perceives two kinds of tree and we may specify the contents of his visual experiences by means of the concepts of birch and beech. However, since he does not himself possess these concepts, there is a natural sense in which the contents of his visual experiences are non-conceptual. ${ }^{3}$

According to the (fairly standard) definition of non-conceptual content I have just relied on, a mental state has non-conceptual content if it can be attributed to a subject without consequently attributing to her possession of the concepts required to specify its content (Crane 1992; Bermúdez 2007).

Cases such as Jacob's suggest that perception operates beyond the level of concept use thus having at least partially non-conceptual content, and this is the orthodox view on the matter today (though see fn 3). The orthodox view is also that the content of belief is fully conceptual. First, in order to form a belief, the subject must possess the concepts that constitute its content. For example, my grandmother believes that in her garden there are beeches and not birches, but would be unable to believe this without possessing the concepts of beech and birch. Second, there is no more to

\footnotetext{
${ }^{3}$ One might claim that differentiating the two kinds of tree on the basis of perception is already a way of grasping the corresponding concepts, albeit in a demonstrative way, as this or that kind of tree (see McDowell 1994). Then the question is whether demonstrative concepts count as bona fide concepts. Even if they do, a further question arises as to whether they are autonomous or must be grounded on a more primitive level of non-conceptual content. After all, in order to know that this tree is different from that tree, there must be different ways of presentation of the trees in perception that precede Jacob's acquisition of the demonstrative concepts (see Evans 1982; Peacocke 1992; Campbell 2002, and many essays in Gunther 2003).
} 
grasping the content of a belief than grasping its conceptual content. ${ }^{4}$

Importantly, some concepts involved in belief are deferential concepts (Millikan 2000; Recanati 2001). That is to say, subjects trust experts with respect to the referent of some constituents of their thoughts. Suppose that, like Jacob, I cannot tell beeches and birches apart, and merely know that the words "beech" and "birch" refer to different kinds of tree, but that my grandmother, whom I trust as an expert gardener, told me that the trees in her garden are beeches and not birches. Then it would seem I can form a belief about the kinds of tree in the garden, since I have reliable sources of information that ground and guide my belief. My belief would count as conceptual, though it involves the deferential concepts that I associate with the words "beech" and "birch". These concepts, however, are not available at the level of perceptual experience. Perceptual content cannot be constituted by deferential concepts (independently of whether there is a deeper, non-conceptual level of perceptual content). The reason for this asymmetry is that belief, unlike perception, depends on various rational capacities, such as critical and reflective thinking, epistemic responsibility and vigilance, etc. These capacities enable the believer to trust non-perceptual, especially testimonial, sources of information.

Many philosophers consider that the conceptual/non-conceptual distinction is a good candidate for distinguishing belief and perception at the level of their contents. Given that CImagination and S-Imagination are akin to belief and perception respectively, might the conceptual/non-conceptual distinction also be used to explain the distinction between them?

\section{CONCEPTUALITY FOR IMAGINATION}

Although the conceptuality dimension has rarely been investigated as such in the literature on imagination, some authors have explicitly hinted at it. Sellars (1978), for instance, suggested that mental imagery is non-conceptual and that imagination is a blend of mental imagery and conceptualization (cited in Currie \& Ravenscroft 2002, p. 101, fn 13). Like many authors McGinn (2004) takes mental imagery to be nothing but S-Imagination (see Arcangeli 2020) and maintains that it has non-conceptual content, whereas C-Imagination has conceptual content. Moreover, he grounds this claim on the respective similarities between S-Imagination and perception, on the one hand, and C-Imagination and belief, on the other (see also Currie \& Ravenscroft 2002, although their view is more complex - see fn 13). In contrast to this influential, albeit overly simplistic picture, I contend that the conceptuality dimension of imagination deserves much more careful

\footnotetext{
${ }^{4}$ Beliefs involving demonstratives can be said to have contents with non-conceptual elements (see, e.g., Burge 1977). But such contents have only derivative non-conceptual elements based on some perceptual presentation (see fn 3 ). Thus, the main idea still holds, namely that for any belief, some conceptual content fully captures what is believed.
} 
analysis.

Imagination in both its guises seems to be conceptually fixed. The claim that the content of CImagination is fully conceptual seems prima facie plausible. How could a subject cognitively imagine that she is a descendent of Cleopatra, or that Zhuangzi's principle is that you cannot get a shi without having a cheng if she does not possess the relevant concepts, which seem to fully capture what is imagined? But the same seems to hold for S-Imagination. For how can a subject sensorily imagine a tiger, or a birch, or a beech, or a "Gran Willy", if the contents of her Simaginings are not fixed by appropriate concepts? Contrary to perception, S-Imagination seems to be conceptually fixed. After all, S-Imagination is essentially dependent on prior conceptual knowledge in a way perception is not (Currie \& Ravenscroft 2002, p. 101). For instance, knowledge of how birches look (e.g., recognitional knowledge about birches) seems to be required in order to visually imagine, but not to see, a birch. Let me elaborate on this intuitive point.

A common thought is that S-Imagination is limited by the "experienced". Hume (1739) first pointed out that we could not (sensorily) imagine anything that we had not previously experienced. And, though we may (sensorily) imagine things "like nothing on earth", such imaginings are intuitively sorts of patchworks ultimately composed of items that have been previously experienced. An interesting reinterpretation of Hume's view is that the ability to sensorily imagine an F requires the subject to have enjoyed certain sensory experiences, namely those that explain the subject's acquisition and possession of the concept of an F. This strongly suggests that the content of SImagination is conceptual.

At least four objections can be raised against the prima facie reasonable view that SImagination has conceptual content. ${ }^{5}$ Before dwelling on them, let me specify the kind of cases I won't consider. Take the case in which I visually imagine, say, a birch in bad light at a great distance. The birch appears in my imagination as a spot, and my imagining might count as a Simagining of a birch, even if I do not possess the relevant concept. My main concern here is sensorily imagining an F as an F, and not merely sensorily imagining of an F. ${ }^{6}$ Moreover, I am not presupposing that sensorily imagining an $\mathrm{F}$ requires sensorily imagining an $\mathrm{F}$ correctly. We can ask what it means to correctly/incorrectly sensorily imagine an F only after having established what it

\footnotetext{
${ }^{5}$ I won't consider a fifth objection which moves from the idea that children (up to a certain age) and non-human animals do not possess concepts and claims that an infelicitous consequence of my view is that children and (most) nonhuman animals do not imagine, contra strong evidence showing that they do. This objection is based on shaky grounds. First, it is not obvious that either young, pre-linguistic children or non-human animals lack concepts, or at least protoconcepts (see Bermúdez 2003; Carey 2009). Second, to what extent non-human animals engage their imagination is still an open question (Mitchell 2016). Likewise, many central questions concerning the development of imaginative abilities in children have not been settled (Skolnick Weisberg 2016).

${ }^{6}$ I am echoing Nelson Goodman's distinction between black-horses pictures and pictures of black horses (see Goodman 1976).
} 
means to sensorily imagine an F, or that there is an $\mathrm{F}$. This paper aims precisely at throwing light on the latter issue.

While I am sitting in my office, I imagine a beautiful birch under which to laze. This is a prototypical exercise of S-Imagination, the kind we do with our eyes closed, so to speak - i.e., without relying on our immediate environment. Elements of our surroundings, however, can be exploited by our S-Imagination. I might look around in my office and sensorily imagine where to put a new plant (most likely not a birch!), or I can sensorily imagine a plant already there (an amaryllis, say) having a beautiful red flower (it never blossomed since I have it). In some of these cases, S-Imagination might seem to have non-conceptual elements in its content, but only because it builds on some independent perceptual presentation (see fn 3 and fn 4 ). ${ }^{7}$ I take these to be complex cases in which S-Imagination somehow blends with perception. ${ }^{8}$ They deserve to be examined, but a proper account cannot be offered without first making clear what would be the contribution of SImagination, that is to say, what it means to sensorily imagine.

With these clarifications in mind, we can turn to more pressing objections against my claim that prototypical S-imaginings have conceptual content.

\subsection{Objection 1: "S-Imagination must match perception along the content dimension"}

A first objection comes from the idea that S-Imagination is relevantly similar to perception, or perception-like in nature. The line of argumentation is as follows: a type of imagination X-I is Xlike, because it parallels its non-imaginative counterpart $\mathrm{X}$ along certain dimensions, one of them being the content dimension. Currie and Ravenscroft suggest this view when they ask: "How could one [imaginative] kind of state have another as counterpart when they don't even have the same kinds of content?" (Currie \& Ravenscroft 2002, p. 101). They take S-Imagination as the mental simulation of perception, so that the latter is the counterpart of the former. Given that perception has non-conceptual content (as many philosophers think), if S-Imagination had conceptual content, it could not have perception as its counterpart. Therefore, the content of S-Imagination must be non-conceptual too, but the possibility can be left open that, if the content of perception turned out to be conceptual, the same would hold for S-Imagination (ibid, p. 102).

It is not clear how Currie and Ravenscroft would justify the view about the content-similarity

\footnotetext{
${ }^{7}$ The same can be said about mental rotation tasks, granting that this widely employed experimental protocol (notably by Shepard \& Metzler 1971) relies on the exploitation of mental imagery qua S-Imagination (the two notions might not coincide, see Arcangeli 2020). Arguably, subjects involved in these experiments do not possess descriptive/theoretical concepts of the complex geometrical figures they are presented with, but they can deploy concepts anchored to perceptual presentations (e.g., demonstrative concepts).

${ }^{8}$ Along similar lines it might be objected that there are cases of $\mathrm{C}$-Imagination with partially non-conceptual content (e.g., I imagine that what looks like this [pointing to water] does not have the chemical structure $\mathrm{H}_{2} \mathrm{O}$ ). It might be replied that these are mixed cases where C-Imagination is aided by perception.
} 
between imaginings and counterparts, which is motivated by their rhetorical question. I suspect that one might rely here on an implausible strong kind of simulationism. According to this version of simulationism, to imagine $\mathrm{X}$-ing is to take "off-line" the very same cognitive mechanism (or set of systems) on which $\mathrm{X}$ relies under normal conditions. For instance, S-Imagination would be the redeployment of the perceptual system disconnected from other cognitive systems with which perception is normally associated, such as action. The one-to-one match between the cognitive basis of a type of imagination and its counterpart would then result in their being alike along most dimensions including the content dimension.

The cognitive sciences have laid the basis for the simulationist hypothesis about imagination, having provided extensive evidence for the similarities of the processes underlying S-Imagination and perception (more precisely vision and audition - see Goldman 2006 for a classic review of the literature). However, as Currie and Ravenscroft acknowledge, the comparative data on S-Imagination and perception do not support the strong version of simulationism, but rather only the claim that a type of imagination exploits some of the mechanisms and processes also underlying its counterpart, while engaging other mechanisms and processes as well (Currie \& Ravenscroft 2002, p. 79 - although the overlap appears to be more limited than what has been traditionally assumed, see Brogaard \& Gatzia 2017; Winlove et al. 2018).

If a one-to-one match between the cognitive base of a type of imagination and its counterpart is not required, then there can be dimensions along which these mental states differ without undermining their similarities. Why should we take the content dimension as crucial to establish the X-like nature of the X-Imagination under scrutiny? Without an answer to this question, it remains mysterious why SImagination and perception should have the same kind of content in order for the former to be the imaginative homologue of the latter.

Certainly, the notion of "same kind of content" is underspecified. It is highly plausible that the content of S-imaginings is less fine-grained than that of perceptual experiences (see, e.g., Sartre 1936; Weatherson 2004; McGinn 2004; Byrne 2010). For instance, I may perceive a sample of crimson red (RGB 220, 20, 60), without being able to capture this determinate shade of red with any visual imagining. The content of visual S-Imagination seems to be more schematic than that of visual perception, and typically picks out classes of determinate shades. Is this difference in content enough to establish that S-Imagination and perception have different kinds of content? Perhaps it is not. Compare a slightly blurry photograph of a sleeping cat and a non-blurry photograph of a sleeping cat. Although the former might be less fine-grained than the latter, there is a sense in which they have the same kind of content. We might say that they do not have exactly the same content, but they might have the same kind of content. Indeed, it has been suggested that both perception and S-Imagination have a sensory 
type of content, though they differ in richness and fine-grainedness. Therefore, Currie and Ravenscroft might be right in claiming that perception and S-Imagination have the same kind of content, but this does not mean that they are perfectly on a par along the content dimension.

A perceptual experience is based on the presentation of maximally determined qualities, because perception puts us in direct contact with external objects which stimulate our senses. This is the reason why perception shows such a fine-grained and rich sensory content, which has usually been taken as evidence in favour of perception having non-conceptual content (locus classicus is Evans 1982). SImagination has a less rich and fine-grained sensory content than the one we can grasp via perception, because it is not stimulus-dependent and relies on prior conceptual knowledge. If a subject possesses the concepts of two slightly different shades of red (corresponding to, e.g., $\operatorname{red}_{38}$ and red $_{40}$ ), ${ }^{9}$ she should be able to sensorily imagine fine-grained colour differences (Langland-Hassan 2011, p. 165). This strongly suggests that S-Imagination has conceptual content. Still, S-imaginings can be seen as more similar to perceptual states than to doxastic states. Hence, a case can be made for the claim that a variety of imagination need not be totally like its counterpart along the content dimension.

Although S-Imagination can somehow mimic perception, it is still a high-level, stimulusindependent faculty which exploits only conceptual abilities. This view is compatible with Currie and Ravenscroft's claim that S-Imagination and C-Imagination have different counterparts, namely perception and belief. Arguably what tightly ties varieties of imagination to their counterparts is to be found in their ways of representing (i.e., the psychological attitudes they are), more than in what they represent (i.e., the type of content they have). Currie and Ravenscroft seem to agree on this point and to maintain that when we X-ly imagine a given content, we grasp such a content in a way similar to $\mathrm{X}$ (Currie \& Ravenscroft 2002, p. 27). Types of imagination, like S-Imagination and C-Imagination, simulate their counterparts by mimicking attitudinal features constituting their cognitive profile (e.g., phenomenological aspects, functional roles). Therefore, claiming that, contrary to perception, SImagination has conceptual content is compatible with the idea that the latter simulates the former, if SImagination still shows phenomenological and functional similarities with perception. Additional arguments are needed for non-conceptualism about the content of S-Imagination. ${ }^{10}$

\footnotetext{
${ }^{9}$ In $\S 4$ I will specify that these concepts need to be observational.

${ }^{10}$ McGinn claims that, like percepts, S-imaginings have non-conceptual content "in the sense that they are intrinsically belief-independent; certainly, they both incorporate "qualia." (McGinn 2004, p. 189 fn 2). However, both the beliefindependence and the phenomenological aspects of S-Imagination can be treated independently of the conceptuality issue. More generally, I am assuming, contra purely intentionalist views (see Nanay 2015 for a reduction of the phenomenal similarity between perception and S-Imagination to the similarity between the structure of their content), that both the attitude and the content contribute to the overall phenomenology of a given mental state.
} 


\subsection{Objection 2: "S-Imagination, like perception, is attitudinally non-conceptual"}

A second objection to the view that S-Imagination has conceptual content draws on a functional difference between perception and belief (qua distinct attitudes), namely the ability to participate in inferences. Some authors have linked the latter to conceptuality. The idea is that being in a mental state with conceptual content requires the possession of inferential abilities involving such mental state (see Crane 1992). For example, my grandmother's belief that there are beeches in her garden is a mental state with conceptual content because it requires an ability to perform certain beech-related inferences on its basis (e.g., infer from her initial belief the additional belief that beeches are common in this part of the country). In contrast, Jacob's visual experience of beeches cannot participate in inferences (whether as something that can be inferred from another mental state, or as something that inferentially gives rise to another mental state), which makes it a mental state with non-conceptual content.

S-Imagination is an attitude similar to perception in this respect; it does not seem to be apt to participate in inferences. As Currie and Ravenscroft put it: "Images [S-imaginings] are not related to one another by inferential dispositions, nor is the having of one or more images ever grounds for saying that the subject ought to have certain other images" (Currie \& Ravenscroft 2002, p. 103). ${ }^{11}$ But, then, by this hypothesis the content of S-Imagination turns out to be non-conceptual as well.

It seems plausible to say that S-imaginings do not have an inferential role, but this feature of SImagination is independent from the notion of conceptuality I have been relying on. Grounding conceptuality on the inferential role of attitudes is different from, and orthogonal to, grounding conceptuality on the possession of the concepts required to specify the given content. Arguably, if an attitude has an inferential role, it requires the possession of appropriate concepts, but the converse is not true. Thus, an attitude can require the possession of the concepts specifying its content, without being apt to participate in inferences. This is precisely what I hold with respect to S-Imagination. Note that we need not sever concept possession from inferential abilities. Visualising a beech might require that the subject be able to make inferences using the concept of a beech, not at the level of $S$ Imagination (for the visual imagining itself lacks inferential role), but at least at the level of belief or CImagination.

The second objection shifts the notion of (non-)conceptuality from the content to the attitude. Regardless of the content - that is, no matter whether the subject possesses the relevant concepts

\footnotetext{
${ }^{11}$ Arguably McGinn has a similar point in mind when he writes: "Of course, images [S-imaginings] become recruited by the conceptual system once it is in place, but it seems doubtful that they are constitutively conceptual. Certainly, imagery [S-Imagination] is consistent with the absence of anything deserving the name of belief and reasoning" (McGinn 2004, p. $170 \mathrm{fn}$ 48). Contrary to McGinn, Langland-Hassan argues that visualization is the occurrence of a belief, but of a kind that might fail tests of compositionality and systematicity, and have non-conceptual content (Langland-Hassan 2011, p. 166). Yet, as he stresses, "everyone concerned to explain the usefulness of visualization has to account for the inferential interaction between visualizations and the beliefs that do satisfy tests of compositionality and systematicity" (ibid.).
} 
specifying it, a type of mental state is non-conceptual in virtue of not having an inferential role.

The two ways of defining (non-)conceptuality highlight two different levels of (non-)conceptuality: an attitudinal level (tied to having or lacking inferential roles), and a content level (tied to possessing or lacking concepts). ${ }^{12}$ On this line of thought, one might hold that belief and perception differ with respect to the former level only - perception would be non-conceptual at the attitudinal level, but not at the content level. One might even go for a more radical stance and claim that perception is non-conceptual also at the content level, thus being different from belief at both levels. Likewise, one might propose a similar strong view for S-Imagination: it would be nonconceptual both at the content and at the attitudinal levels. However, this does not seem a plausible view, given that, contrary to perception, S-Imagination recruits prior conceptual knowledge. We should rather go for the weaker claim that while S-Imagination is non-conceptual at the attitudinal level, it is conceptual at the content level. ${ }^{13}$ Therefore, I concede to the holder of the second objection that S-Imagination is in a pertinent sense non-conceptual, but contend that it does not refer to the content level we are focusing in; on this level S-Imagination is conceptual.

\subsection{Objection 3: "Passive S-imaginings have non-conceptual content"}

So far I have offered good reasons to think that the content of S-Imagination is conceptual (conceptual knowledge is required by S-imagination, which is a high-level faculty recruiting a concept for each constituent of its content and this is manifest in the level of richness and finegrainedness shown by the latter). I have also blocked two arguments in favour of the idea that the content of S-Imagination is fully conceptual.

It might be objected, however, that my view applies only to some S-imaginings, namely active or intentionally produced S-imaginings. These imaginings are likely to have conceptual contents, insofar as they are grounded on conceptual knowledge that the imaginer intentionally recruits. If I deliberately sensorily imagine a sleeping cat on the sofa, I must possess the concepts specifying the content of my S-imagining. The objection goes on to argue that not all S-imaginings are intentional.

\footnotetext{
${ }^{12}$ These two levels of (non-)conceptuality echo the distinction between the state view and the content view (see Heck 2000). The former defines non-conceptuality as being a concept-independent type of mental state, the latter as having a specific type of content. Although these views have been taken as alternatives, it might be that we should think of them as highlighting different but compatible senses of "non-conceptual", dealing with the aforementioned levels of (non-)conceptuality. Still, holders of the state view seem to be committed to a specific view of the content level and would not allow, as I am suggesting, concept-independent mental states with conceptual content.

13 This view is partly consonant with Currie and Ravenscroft's preferred view. They claim that "imagery is nonconceptual, not in the sense of having an especially nonconceptual content, but in the sense of being a state, the functional role of which does not require of its possessor the kind of discriminatory and inferential powers that in turn depend on concept possession" (Currie \& Ravenscroft 2002, p. 106). However, if at the content level - as I am suggesting - S-Imagination conceptually differs from perception, such a difference fails to meet Currie and Ravenscroft's demand of being alike along this dimension. Once again some pressure is put on the strong claim about the relationship between imaginings and counterparts with respect to the content level. The easy way out is to give up such a demand.
} 
There are unbidden S-imaginings, imaginings that come to, and can haunt us in spite of our will (e.g., a shocking scene from a series).

Currie and Ravenscroft suggest that spontaneous S-imaginings "can represent to us colours and shapes we have seen fleetingly and forgotten - items of which we have no concept" (Currie \& Ravenscroft 2002, pp. 104-105). They offer hypnagogic images as exemplifying such a case. Along similar lines, eidetic (or photographic) memories might be offered as another example of passive Simaginings with non-conceptual content. People with eidetic memories are apparently able to recall events with such a degree of detail, vividness and stability that what they recall feels as part of their present sensory environment. These experiences are often associated with looking at photographs and are reported to be more like passively perceiving than actively conjuring up mental images (Thomas 2014). Eidetic memories might be seen as hinging on S-imaginings whose contents can have the same richness and fine-grainedness as perceptual content, thus being non-conceptual.

Spontaneous imaginings are a widely discussed phenomenon relevant to the issue of the voluntariness of imagination (or lack thereof). They put pressure on the claim that all imaginings are dependent on the will, making a case for the idea that imagination can be involuntary - although some have maintained even such imaginings are voluntary (e.g., Kind 2001; Ichikawa 2009; Arcangeli 2018). At any rate, it is not clear why S-imaginings being will-dependent or else should matter for determining the conceptuality of their contents. Both belief and perception are will-independent, but their contents differ: while the former has conceptual content, the latter has non-conceptual content. Thus, even granting that some S-imaginings are genuinely involuntary, this does not straightforwardly imply that they have non-conceptual content. After all, our concepts can be (and usually are) recruited independently of our will.

Regarding hypnagogic images and eidetic memories, these are far from being compelling cases. Thus, they cannot be used in arguments in favour of the non-conceptuality of some S-imaginings contents. Hypnagogic images involve a state at the threshold of consciousness, in between sleep and wakefulness, which comprises hallucinatory elements. How imagination relates to dreams and hallucinations are notably vexed issues (see, e.g., Kind 2001 and Ichikawa 2009). Moreover, an old tradition (which can be traced back to Aquinas - see De Brigard 2017, pp. 132-133) holds that not all mental images are imaginative (see also White 1990; Kind 2001; Arcangeli 2020). Therefore, it is debatable whether hypnagogic images count as S-imaginings.

Similarly, also eidetic memories are hard to assess. First, the existence of the very psychological phenomenon has been questioned (Schwitzgebel 2002). Second, even granting that eidetic memories exist, it is an open question whether they involve sensory imaginings with non-conceptual content. One could deny that eidetic memory involves S-Imagination. It is widely agreed that recollection (or 
episodic memory) typically involves re-living an episode of one's own past, and thus exploits our Simagination (Schacter \& Addis 2007; Michaelian 2016; Hopkins 2018). Yet it is far from clear that this is always the case: episodic memory is plausibly a different attitude that can come without SImagination. ${ }^{14}$ Therefore, eidetic memory might not involve the latter. Alternatively, it might be conceded that eidetic memories involve S-imaginings, but dispute that the latter have non-conceptual content. The idea is that what is at stake in these cases has more to do with density of information than quality. S-imaginings involved in eidetic memories would represent more details than standard Simaginings, but they would not do that in a more determined way. Those S-imaginings would still have contents less rich and fine-grained than those of perception, thus plausibly being conceptual (\$3.1).

To sum up, phenomena such as hypnagogic images and eidetic memories provide shaky grounds at best on which to build a strong case for the non-conceptuality of (some) S-imaginings contents.

\subsection{Objection 4: "The content of S-Imagination has a non-conceptual layer"}

My opponent might accept that S-Imagination needs to recruit concepts, but yet claim that conceptuality captures only part of S-Imagination content. A fourth objection to my view is that I have not excluded the possibility that at least part of the latter is non-conceptual. The idea is that SImagination has two content layers: a conceptual and a non-conceptual one. To a closer examination, however, the claim that S-Imagination has partially non-conceptual content proves to be unstable.

The pressing question is: once we have acknowledged that the content of S-Imagination must have a conceptual layer, what would be the explanatory role of an additional non-conceptual layer of content? It is hard to answer this question. One hypothesis is that such a layer accounts for the manifest properties of the imagined scene, in line with the two content view of S-Imagination, which claims that it "has two kinds of content, qualitative content and assigned content" (Kung 2010, p. 632). For instance, when I sensorily imagine a sleeping cat on the sofa, my S-imagining is about (a) shapes and colours, and (b) the fact that there is a sleeping cat on the sofa, rather than a jumper which looks like a sleeping cat.

On the two content view, my S-imagining has two content layers: qualitative content - (a), and assigned content - (b). Qualitative content captures manifest properties and is modelled by Kung on Peacocke's notion of "scenario content" (Peacocke 1992), which is meant to grasp the most basic nonconceptual layer of perceptual content. Hence, it might be argued that while qualitative content is nonconceptual, assigned content is conceptual.

\footnotetext{
${ }^{14}$ A lively debate as to the role of imagination in memory sees both reductionist views of episodic memory, which depict it as nothing but a specific use of the imagination (e.g., Michaelian 2016 and Hopkins 2018), and dissenting voices (e.g., Perrin 2016; Debus 2014; Fernandez 2017).
} 
The weakness of this argument lies in failing to specify why qualitative content (qua bearer of manifest properties) must be non-conceptual. Kung seems to be aware of this problem and prefers to remain neutral with respect to the non-conceptuality of qualitative content. ${ }^{15}$ Even granting that SImagination has a two-layered content, it is not clear why one of the two layers should be nonconceptual. The idea that both layers are conceptual is nicely suggested by Wiltsher in the following comment on Kung's view:

when we imagine, the world doesn't provide the scenario; nor does it provide a context in which that scenario is interpreted. (...) Plausibly, these things are in the gift of the subject You actively generate an image [S-imagining or S-imagining content] by deploying a concept. (...) My suggestion about images is that a concept always figures in the story, and always exerts this influence (Wiltsher 2016, pp. 272-273).

Arguably, once it is acknowledged that S-Imagination must have conceptual content, there is no explanatory role left for an additional layer of non-conceptual content. For a perceptual experience to have at least partially non-conceptual content, it must come directly from the subject's present experience - i.e., from a direct non-conceptual contact with the world. Beforehand I have stressed that such stimulus-dependence is not available to S-Imagination, since it does not hinge on there being anything before our eyes when we are imagining (as also pointed out by Wiltsher).

If both sensory and cognitive imagination have conceptual content, is the conceptuality dimension still relevant to draw the distinction? A sceptical answer would be that the distinction itself between S-Imagination and C-Imagination is wrongheaded. However, this answer strikes me as premature and in the next section I will suggest how conceptuality can still play a crucial role in distinguishing between these two varieties of imagination.

\section{OBSERVATIONAL CONCEPTS FOR SENSORY IMAGINATION}

I have never played tennis, or even watched tennis matches, whereas my father is a tennis fan and a fairly good player. One day my father told me that he had (sensorily) imagined hitting a Gran Willy (or tweener) playing with Guillermo Vilas, who was the first to use this characteristic shot. My father made it clear that a Gran Willy is a between-the-legs, inside-out forehand and is a last resource shot used only when the ball has passed the player and she has to run for it with the net at her back. If done well, it is very effective because the opponent cannot watch where the ball is going until it is too late.

In parallel with the case of my grandmother's garden, we may say that I possess the concept of Gran Willy deferentially, i.e., via my father's explanation. Deferential concepts can be seen as

\footnotetext{
${ }^{15}$ He specifies: "Though my take on qualitative content owes much to Peacocke, I remain neutral on whether qualitative content is 'conceptual' or 'nonconceptual'” (Kung 2010, p. 623, fn 7).
} 
paradigm examples of non-observational concepts. The distinction between observational and nonobservational concepts is notoriously difficult to define precisely (see Peacocke 1983, 1986, 1992 and Bermúdez 2007), but the following rough gloss will suffice for our purposes here: the concept of an $F$ is observational, if it can be directly applied on the basis of perceptual experience alone, typically via a demonstrative judgement of the form "This is an $\mathrm{F}$ ". ${ }^{16}$

My concept of Gran Willy is non-observational. In order to have an observational concept of Gran Willy, I would have at a minimum to watch some tennis games, which I never do. Now, it is plausible that the ability to sensorily imagine a Gran Willy requires such an observational concept (in line with the reinterpretation of Hume’s view I suggested in §3). In other words, possessing a nonobservational concept of an $\mathrm{F}$ is not sufficient to be able to sensorily imagine an $\mathrm{F}$. Thus, given my conceptual repertoire, I cannot sensorily imagine a Gran Willy (either done by myself or another player). ${ }^{17}$

Of course, if no observational concept of an $\mathrm{F}$ is independently available (e.g., the concept of burning water, or the concept of a unicorn), one may try to sensorily imagine an $\mathrm{F}$ by combining other observational concepts (say the concepts burning and water, or the concepts of horse and horn). It might even be that I can acquire a new observational concept on the basis of my creative imaginings. The point still holds that all cases of S-Imagination require observational concepts, and cannot be based on mere non-observational (e.g., deferential) concepts.

It might be objected that I may visually imagine a situation in which my dad hits a Gran Willy, for instance a match in which Vilas is screaming "Damned, my shot against me!". The phrase "visually imagine a situation in which $p$ " does not require ascribing the concepts constituting the proposition that $p$ (see Williamson 2000 who makes an analogous claim for the phrase "perceive a situation in which $p$ "), whether they are construed as observational or not. Hence, the content of my visual imagining could be non-conceptual.

Similarly, though I am not able to sensorily imagine a birch, if I merely know that a birch is a kind of tree, I may visually imagine a situation in which there is a birch. For example, I may imagine a trip in a botanic garden and a guide who tells us that on the left we have some rare

\footnotetext{
${ }_{16}$ Observational concepts can be demonstrative ("this shade of red"), but they need not (the concept "red" is observational but it is not demonstrative). Classical examples of observational concepts seem to be phenomenal concepts (like concepts of shapes and colours), but the latter might not exhaust the former. One might think that the notion of observational concepts hinges on the non-conceptuality of perception. For instance, one might argue that part of the possession conditions of an observational concept is that the subject's deployment of the concept is sensitive to perceptual experiences with appropriate non-conceptual contents (e.g., Peacocke 1992). However, one can also give an account of the possession conditions of observational concepts while being neutral about the content of perception (see Bermúdez 2007, p. 71 fn 13).

${ }^{17}$ To sensorily imagine a Gran Willy is to sensorily imagine hitting a Gran Willy. It might be that sensorily imagining an action involves concepts belonging to a specific class of observational concepts which require the acquisition of appropriate practical knowledge.
} 
birches. And along these lines we may give an account for each of the examples mentioned in $\S 3$, granting that the subject does not possess the relevant concepts (i.e., tiger and beech).

These alleged counterexamples do not easily show that S-Imagination can be non-conceptual. An initial response is that they do not involve non-conceptual imaginings, but rather imaginings whose contents exploit deferential concepts. These deferential concepts are admittedly nonobservational, though. Accordingly, the full response is that "imagining a situation in which $p$ " is in reality a hybrid state composed of a $\mathrm{C}$-imagining that $p$ and a $\mathrm{S}$-imagining of an aspect of the state of affairs that $p$. Thus, in the above case of imagining a situation in which there is a birch, there is a C-Imagination component that exploits a deferential concept of birch, along with a S-Imagination component that deploys my observational concept of a generic tree.

In summary, my suggestion is that the distinction between observational and non-observational concepts is a plausible path to take in order to distinguish S-Imagination and C-Imagination: the former requires the exclusive use of observational concepts, whereas the latter does not. This is not to say that $\mathrm{C}$-Imagination requires non-observational concepts; one can cognitively imagine that bears are extinct by using an observational concept of bear. ${ }^{18}$ The idea is that S-Imagination, as a variety of imagination, imposes a constraint on its conceptual content that C-Imagination does not. This is as far as we can get, I surmise, with respect to the conceptual dimension of imagination and the distinction between sensory, perception-like imagination and cognitive, belief-like imagination.

\section{CONCLUSION}

The conceptuality dimension has been thoroughly explored to set perception and belief apart. Surprisingly, it has been almost completely neglected in explaining the distinction between sensory and cognitive imagination. The implicitly accepted, though rarely motivated, claim is that SImagination has fully (or at least partially) non-conceptual content, whereas C-imagination has fully conceptual content. I raised doubts against this simplistic claim and advanced two hypotheses.

First, the notion of non-conceptual content does not seem to play any role in S-Imagination, whose content is plausibly construed as fully conceptual. It is impossible to set out to sensorily imagine a tiger without possessing the concept of a tiger and once such a conceptual layer is acknowledged, there is no explanatory role left for an additional layer of non-conceptual content. The

\footnotetext{
${ }^{18}$ One might wonder what distinguishes a C-imagining that happens to involve only observational concepts from a Simagining with the same content (e.g., I cognitively vs. sensorily imagine that bears are green). Here what has been said about having inferential roles can be helpful (\$3.2): the former, but not the latter, will entail state-specific inferential abilities, at least if C-imaginings, like beliefs, can enter into inferential relations (see Currie \& Ravenscroft 2002; Weinberg \& Meskin 2006; Arcangeli 2018). An alternative proposal is that whenever the content of an imagining is fully observational, it counts as a case of S-Imagination.
} 
upshot is that the conceptual/non-conceptual distinction cannot neatly distinguish the two varieties of imagination.

It does not follow that we should abandon the distinction between S-Imagination and CImagination, though. My second hypothesis is that differences in the types of concepts employed distinguish the two varieties of imagination: contrary to C-Imagination, S-Imagination requires observational concepts.

\section{REFERENCES}

Arcangeli, M. 2018. Supposition and the Imaginative Realm. A Philosophical Inquiry. Routledge.

Arcangeli, M. 2020. "The Two Faces of Mental Imagery". Philosophy and Phenomenological Research 101(2): 304-322.

Bermúdez, JL 2003. Thinking Without Words. OUP.

Bermúdez, JL. 2007. “What Is at Stake in the Debate on Nonconceptual Content?”. Philosophical perspectives 21(1): 55-72.

Brogaard, B. \& Gatzia, D. E. 2017. "Unconscious Imagination and the Mental Imagery Debate". Front. Psychol. 8:799 doi: 10.3389/fpsyg.2017.00799.

Burge, T. 1977. "Belief de re". Journal of Philosophy 74 (6): 338-362.

Byrne, A. 2010. "Recollection, perception, imagination". Philosophical Studies 148(1): 1-12.

Campbell, J. 2002. Reference and consciousness. OUP.

Carey, S. 2009. The Origin of Concepts. OUP.

Crane, T. 1992. The Contents of Experience: essays on perception. CUP.

Crane, T. 2009. “Is Perception a Propositional Attitude?”. The Philosophical Quarterly 59(236): $452-469$.

Currie, G. \& Ravenscroft, I. 2002. Recreative minds: Imagination in philosophy and psychology. OUP.

De Brigard, F. 2017. Memory and Imagination. In The Routledge Handbook of Philosophy of Memory, eds. Bernecker, S. \& Michaelian, K. (127-140). Routledge. 
Debus, D. 2014. “"Mental Time Travel': Remembering the Past, Imagining the Future, and the Particularity of Events”. Review of Philosophy and Psychology, 5: 333-350.

Dretske, F. 1969. Seeing and knowing. University of Chicago Press.

Evans, G. 1982. The varieties of reference. OUP.

Fernandez, J. 2017. The Intentional Objects of Memory. In Routledge Handbook of Philosophy of Memory, eds. Bernecker, S. \& Michaelian, K. (88-99). Routledge.

Goldman, A. 2006. Simulating Minds: the Philosophy, Psychology, and Neuroscience of Mindreading. OUP.

Goodman, N. 1976. Languages of Art: An Approach to a Theory of Symbols (2nd edition). Hackett Publishing Company.

Gunther, Y. (ed) 2003. Essays on Nonconceptual Content. MIT Press.

Heck, R.G. 2000. "Nonconceptual Content and the 'Space of Reasons"”. The Philosophical Review 109(4): 483-523.

Hopkins, R. 2018. Imagining the Past: On the Nature of Episodic Memory. In Perceptual Imagination and Perceptual Memory, eds. Dorsch, F. \& MacPherson, F., (47-70). OUP.

Hume, D. 1739. A Treatise of Human Nature. J. Noon.

Ichikawa, J. 2009. “Dreaming and imagination”. Mind \& Language 24(1), 103-121.

Kind, A. 2001. "Putting the image back in imagination". Philosophy and Phenomenological Research 62(1), 85-109.

Kind, A. 2013. “The heterogeneity of the imagination”. Erkenntnis, 78(1), 141-159.

Kind, A. 2016. Introduction: exploring imagination. In The Routledge handbook of philosophy of imagination, ed. Kind, A., (1-11). Routledge.

Kung, P. 2010. "Imagining as a Guide to Possibility". Philosophy and Phenomenological Research 81(3): 620-63.

Langland-Hassan, P. 2011. “A puzzle about visualization”. Phenom Cogn Sci 10: 145-173.

McDowell, J. 1994. Mind and world. Harvard University Press.

McDowell, J. 2008. Avoiding the Myth of the Given. In John McDowell: Experience, Norm, and Nature, ed. Lindgaard, J. (1-14). Blackwell. 
McGinn, C. 2004. Mindsight: image, dream, meaning. Harvard University Press.

Michaelian, K. 2016. Mental Time Travel. Episodic Memory and Our Knowledge of the Personal Past. Cambridge. MIT Press.

Millikan, R. G. 2000. On clear and confused ideas: an essay about substance concepts. CUP.

Mitchell, R. W. 2016. Can animals imagine?. In The Routledge handbook of philosophy of imagination, ed. Kind, A. (326-338). Routledge.

Nanay, B. 2015. "Perceptual content and the content of mental imagery". Philosophical Studies 172: $1723-1736$.

Peacocke, C. 1983. Sense and content: experience, thought, and their relations. Clarendon Press.

Peacocke, C. 1986. Thoughts: An Essay on Content. Blackwell

Peacocke, C. 1992. A Study of Concepts. MIT Press.

Perrin, D. 2016. Asymmetries in Subjective Time. In Seeing the Future. Theoretical Perspectives on Future-oriented Mental Time Travel, eds. Michaelian, K., Klein, S. B. \& K. K. Szpunar (39-61). OUP.

Recanati, F. 2001. Modes Of Presentation: Perceptual vs Deferential. In Building on Frege: New Essays on Sense, Content, and Concept, eds. Newen, A., Nortmann, U., \& Stuhlmann-Laeisz, R. (197-208). CSLI Publications.

Sartre, J. P. 1936. L'imagination. Presses Universitaires de France.

Schacter, D. L., \& Addis, D. R. 2007. "The Cognitive Neuroscience of Constructive Memory: Remembering the Past and Imagining the Future". Philosophical Transactions of the Royal Society of London. Series B: Biological Sciences, 362(1481): 773-786.

Schwitzgebel, E. 2002. "How Well Do We Know Our Own Conscious Experience? The Case of Visual Imagery”. Journal of Consciousness Studies, 9(5-6): 35-53.

Sellars, W. 1978. The role of imagination in Kant's theory of experience. In Categories: A Colloquium, 231-245. Pennsylvania State University Press.

Shepard, R. N., \& Metzler, J. 1971. "Mental Rotation of Three-Dimensional Objects". Science 171: $701-703$.

Skolnick Weisberg, D. 2016. Imagination and child development. In The Routledge handbook of philosophy of imagination, ed. Kind, A. (300-313). Routledge. 
Szabó, Z. 2003. "Believing in things". Philosophy and Phenomenological Research, 66(3), 584611.

Thomas, N. J. 2014. Mental Imagery. In The Stanford Encyclopedia of Philosophy (Summer 2019 Edition) ed. Zalta, E. N., https://plato.stanford.edu/archives/sum2019/entries/mental-imagery/ .

Weatherson, B. 2004. "Morality, fiction, and possibility". Philosopher's Imprint 4(3): 1-27.

Weinberg, J. \& Meskin, A. 2006. Puzzling over the Imagination: Philosophical Problems, Architectural Solutions. In The Architecture of the Imagination: New Essays on Pretence, Possibility, and Fiction, ed. Nichols, S. (175-202). OUP.

White, A. 1990. The language of imagination. Blackwell.

Williamson, T. 2000. Knowledge and its limits. OUP.

Wiltsher, N. 2016. "Against the Additive View of Imagination”. Australasian Journal of Philosophy 94(2): $266-82$.

Winlove, C., Milton, F., Ranson, J., Fulford, J., MacKisack, M., Macpherson, F. \& Zeman, A. 2018. "The neural correlates of visual imagery: A co-ordinate-based meta-analysis". Cortex 105: 2640.

Yablo, S. 1993. "Is Conceivability a Guide to Possibility?". Philosophy and Phenomenological Research 53: 1-42. 